\title{
Renal effects of aspirin and low dose methotrexate in rheumatoid arthritis
}

Department of
Internal Medicine,
Division of
Rheumatology,
Karolinska Institute,
Danderyd Hospital,
S-182 88 Danderyd,
Sweden
P Seideman
Department of Clinical
Physiology,
Karolinska Institute,
Danderyd Hospital,
S-182 88 Danderyd,
Sweden
R Müller-Suur
Correspondence to:
Dr Seideman.
Accepted for publication
23 February 1993

Department of Division of Rheumatology, Karolinska Institute,

Department of Clinical Physiology,

Karolinska Institute, Danderyd Hospital Swede

Rüler-Suur

23 February 1993 may also influence renal function by the inhibition of renal prostaglandin synthesis which may lead to a reduction in renal blood flow and the glomerular filtration rate. Aspirin is a potent inhibitor of prostaglandin synthesis and may therefore alter the clearance of methotrexate during the treatment of RA. Concomitant methotrexate and aspirin may therefore reduce systemic and renal clearance of methotrexate. A pharmacokinetic interaction between these drugs has been claimed. The mechanism of this potential interaction is unknown, but changes in renal function are a possible explanation. Changes in the clearance of methotrexate may increase its plasma concentration and thereby increase the risk of toxicity.

The aim of the present investigation was to study the glomerular and tubular effects of low doses of methotrexate during combined treatment with and without aspirin.

\section{Patients and methods}

Eleven patients (10 women) with classical or definite RA were included in the study after informed consent. Their mean age was 55 years (range $32-75$ years). The mean duration of the disease was two years (range 0.5-6). All patients had active disease with ongoing inflammation with a mean erythrocyte sedimentation rate (Westergren) of $47 \mathrm{~mm} / \mathrm{h}$ (range 32-71) at the beginning of the study and $29 \mathrm{~mm} / \mathrm{h}$ (range 12-44) at the end of the study. No patient had a history or clinical signs of renal disease. They all had normal serum creatinine during the study $(65-98 \mu \mathrm{mol} / \mathrm{l})$ and routine urine analyses were normal. No other concomitant drugs such as antihypertensive drugs, diuretics, or other NSAIDs were taken during the investigation.

Plasma clearance studies were performed before treatment with methotrexate was started and thereafter three times during ongoing treatment with methotrexate (15 mg weekly) by mouth. Clearance studies were performed after a mean of three weeks (range two to eight weeks), five weeks (range three to 12 weeks), and 20 weeks (range 16-24 weeks) of treatment with methotrexate. The methotrexate dose was given in the morning just before the clearance study was started. Aspirin ( $2 \mathrm{~g}$ by mouth) was combined with methotrexate at the third clearance study, i.e. after a mean of five weeks of treatment with methotrexate. On that occasion methotrexate $(15 \mathrm{mg})$ and aspirin $(2 \mathrm{~g})$ were given concomitantly by 
mouth in the morning before the clearance study was started. The investigation was approved by the local ethics committee.

\section{CLEARANCE STUDIES}

Dimercaptoacetyltriglycerine labelled with $10 \mathrm{MBq}$ technetium-99m ( ${ }^{99 \mathrm{~m}} \mathrm{Tc}-\mathrm{MAG}-3$; Mallinkrodt Petten, the Netherlands) was injected intravenously as a bolus. The labelling kit was prepared up to 60 minutes before injection (10 samples) with a radiochemical purity of $97.9(0.9) \%$ as measured by high performance liquid chromatography. ${ }^{5}$ Sixty minutes after injection a blood sample was taken from the contralateral forearm. Plasma clearance of ${ }^{99 \mathrm{~m}} \mathrm{Tc}-\mathrm{MAG}-3$ was calculated according to the method of Müller-Suur $e t a l^{5}$ using the formula $y=557 \quad\left(1-\mathrm{e}^{-0.01129(\mathrm{x}-3 \cdot 5)}\right)$, where $y$ is the ${ }^{99 m}$ Tc-MAG-3 clearance and $x$ the distribution volume of ${ }^{99 \mathrm{~m}}$ Tc-MAG-3 at 60 minutes after injection (estimated in litres). The distribution volume was calculated by dividing the injected dose by the measured plasma activity at 60 minutes. The calculated clearance was corrected for body surface area to give clearance for $1.73 \mathrm{~m}^{2}$. Directly after collection of the ${ }^{99 \mathrm{~m}} \mathrm{Tc}-\mathrm{MAG}-3$ plasma sample, $3.7 \mathrm{MBq}^{51} \mathrm{Cr}$-EDTA (Behring-Werke, Marburg, Germany) was injected intravenously through the same cannula as ${ }^{99 \mathrm{~m}} \mathrm{Tc}-$ MAG-3 and 180, 200, 220, and 240 minutes after injection, plasma samples were taken from the opposite forearm. Plasma clearance of ${ }^{51} \mathrm{Cr}$-EDTA was calculated according to Bröchner-Mårtensson and Rödbro $^{6}$ and corrected for body surface area.

All samples were counted in a well type counter and corrected for background and decay. Standards of ${ }^{99 m}$ Tc-MAG-3 and ${ }^{51} \mathrm{Cr}-$ EDTA were measured and the exact dose given was estimated from the standard activity corrected for decay and the weight difference between the filled and empty injection syringe.
STATISTICAL ANALYSIS

Analysis was by non-parametric tests using the Wilcoxon signed rank test for paired observations. $p$ Values less than 0.05 were considered to be significant. Mean (SEM) values are given.

\section{Results}

Clearance ranges of ${ }^{99 \mathrm{~m}} \mathrm{Tc}-\mathrm{MAG}-3$ at baseline were from 281 to $513 \mathrm{ml} / \mathrm{min} \times 1.73 \mathrm{~m}^{2}$. The baseline ${ }^{51} \mathrm{Cr}$-EDTA plasma clearance was $76-150 \mathrm{ml} / \mathrm{min} \times 1.73 \mathrm{~m}^{2}$. After about three weeks of treatment with methotrexate (15 mg weekly) a significant decrease $(\mathrm{p}<0.001)$ of ${ }^{99 \mathrm{~m} T \mathrm{~T}-M A G-3}$ clearance from 366 (18) to 315 (17) $\mathrm{ml} / \mathrm{min} \times 1.73 \mathrm{~m}^{2}$ and of ${ }^{51} \mathrm{Cr}$-EDTA plasma clearance from 98 (6) to 87 (5) $\mathrm{ml} / \mathrm{min} \times 1.73 \mathrm{~m}^{2}$ was observed (see figure). Clearance of ${ }^{99 \mathrm{~m}} \mathrm{Tc}-\mathrm{MAG}-3$ decreased further to $295(17 \cdot 4) \mathrm{ml} / \mathrm{min} \times$ $1.73 \mathrm{~m}^{2}(\mathrm{p}<0.01)$ and ${ }^{51} \mathrm{Cr}-$ EDTA clearance to $76(5) \mathrm{ml} / \mathrm{min} \times 1.73 \mathrm{~m}^{2}(\mathrm{p}<0.001)$ as aspirin was added to the methotrexate treatment. At the last measurement after 16-24 weeks of treatment with methotrexate a further decrease of ${ }^{99 \mathrm{~m}} \mathrm{Tc}-\mathrm{MAG}-3$ clearance to 253 (17) $\mathrm{ml} / \mathrm{min} \times 1.73 \quad \mathrm{~m}^{2}$ was observed $(\mathrm{p}<0.001)$. Clearance of ${ }^{51} \mathrm{Cr}$-EDTA increased significantly, however, to 85 (6) $\mathrm{ml} / \mathrm{min} \times$ $1.73 \mathrm{~m}^{2} \quad(\mathrm{p}<0.01)$. The ratio between the clearances was not changed from the first to the second or to the third investigation, but significantly increased at the fourth investigation $(p<0.001)$ (see figure).

\section{Discussion}

It has long been known that treatment with high doses of methotrexate may affect kidney function, but the effects of low doses of methotrexate are unknown. Aspirin is one of the most widely used therapeutic substances in humans. Despite the proliferation in the
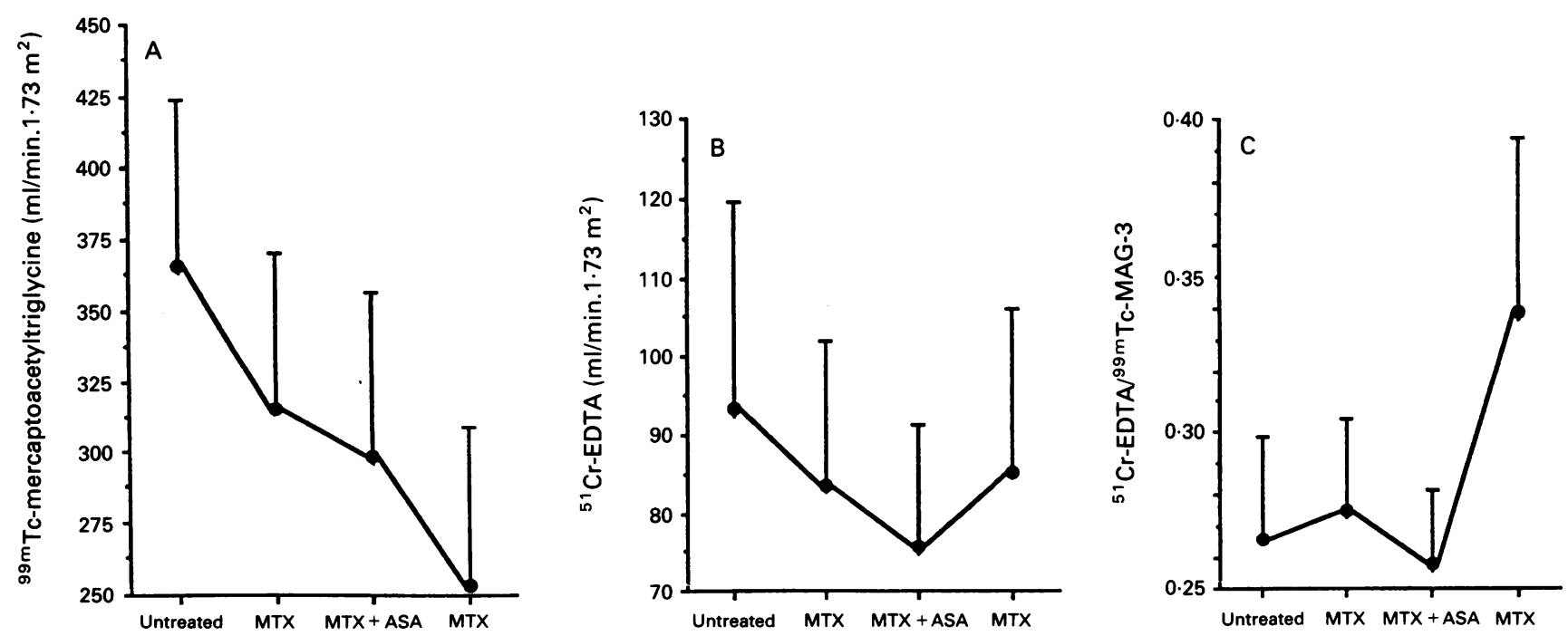

(A) Mean (SEM) clearance of mercaptoacetyltriglycerine labelled with technetium-99m ( $\left.{ }^{9 m} T c-M A G-3\right)$ in 11 patients before treatment, after the first $15 \mathrm{mg}$ dose of methotrexate, after combined treatment with methotrexate and aspirin $(2 \mathrm{~g})$ and after continued treatment with methotrexate (15 mg) only. (B) Mean (SEM) clearance of EDTA labelled with chromium-51 ( $1 \mathrm{Cr}-E D T A)$ in 11 patients before treatment, after the first 15 mg dose of methotrexate, after combined treatment with methotrexate and aspirin $(2 \mathrm{~g})$, and after continued treatment with methotrexate (15 mg) only. (C) Mean (SEM) ratio between ${ }^{51} \mathrm{Cr}-E D T A$ clearance and ${ }^{99 m} \mathrm{Tc}-M A G-3$ clearance in 11 patients before treatment, after the first $15 \mathrm{mg}$ dose of methotrexate, after combined treatment with methotrexate and aspirin $(2 \mathrm{~g})$, and after continued treatment with methotrexate (15 $\mathrm{mg})$ only. 
number of NSAIDs, aspirin remains an important drug in the treatment of rheumatic diseases. Combined treatment with aspirin and methotrexate is therefore often prescribed for rheumatic diseases.

The major findings of the present study are that long term renal function may be decreased by treatment with methotrexate and that aspirin further impairs kidney function in patients treated with methotrexate.

The glomerular filtration rate was measured as the plasma clearance of ${ }^{51} \mathrm{Cr}$-EDTA and it showed a significant decrease in all patients treated with methotrexate and during combined treatment with aspirin. As day to day variations in determinations of glomerular filtration rate using this method are only about $5 \%{ }^{67}$ the observed decrease in ${ }^{51} \mathrm{Cr}$-EDTA clearance reflects true changes in the glomerular filtration rate. After stopping treatment with aspirin, glomerular filtration rate increased, which indicates a separate effect of aspirin.

The renal effects of aspirin observed during combined treatment with methotrexate may be caused by several mechanisms. Aspirin may inhibit renal prostaglandin synthesis via the inhibition of cyclo-oxygenase, leading to a reduction in the glomerular filtration rate, particularly when there is also a reduction in renal blood flow. Our finding of a reversible decrease in the glomerular filtration rate during treatment with aspirin agrees with such a hypothesis. Similar decreases of the glomerular filtration rate have been observed during treatment with other NSAIDs only - for example, indomethacin. ${ }^{8}$

A reduction of renal plasma flow may also be a possible mechanism for the observed decrease in ${ }^{99 m}$ Tc-MAG-3 clearance during treatment with methotrexate and aspirin. Clearance of ${ }^{99 \mathrm{~m}} \mathrm{Tc}-\mathrm{MAG}-3$ has been shown to correlate well with renal plasma flow in a variety of circumstances. ${ }^{9-11}$ As the decrease in ${ }^{99 m}$ Tc-MAG-3 clearance was not reversible, however, as was the ${ }^{51} \mathrm{Cr}$-EDTA clearance, other mechanisms have to be considered. A direct effect of methotrexate and aspirin on the secretion process of ${ }^{99 \mathrm{~m}} \mathrm{Tc}-\mathrm{MAG}-3$ may be one possibility. Direct invasive measurement of renal MAG-3 extraction is necessary to validate this hypothesis, which was not carried out in the present study. Of interest is our finding that ${ }^{99 m}$ Tc-MAG-3 clearance progressively decreased although aspirin was given only once. A time effect of prolonged methotrexate treatment may be involved. The design of this study cannot answer this question and further experiments are necessary.
Renal function impairment due to treatment with NSAIDs alone may be underestimated as it is often asymptomatic. ${ }^{12}$ The clinical importance of renal effects of methotrexate alone or its effect during combined treatment with aspirin as shown here remains to be elucidated.

Side effects on the gastrointestinal and pulmonary systems due to methotrexate treatment are mainly found in elderly patients. Increased hepatic enzyme levels are more often found in patients receiving combined salicylates and methotrexate, and patients with nephritis show side effects more often than patients with normal kidney function. All these observations indicate that methotrexate elimination may deteriorate due to the impairment of renal function.

In summary, this study has shown that treatment with low doses of methotrexate alone or combined with aspirin may decrease the glomerular filtration rate and tubular secretion as assessed by ${ }^{51} \mathrm{Cr}$-EDTA and ${ }^{99 \mathrm{~m}} \mathrm{Tc}$ MAG-3 clearance. These effects may be of clinical importance and renal function should therefore be monitored with more sensitive methods than serum creatinine as this may not reflect these changes.

The skilful technical assistance of Eva Ekman and the staff a the department of hospital physics is acknowledged.

1 Ellison $\mathrm{N} \mathrm{M}$, Servi $\mathrm{R} J$. Acute renal failure and death following sequential intermediate dose methotrexate and 5-FU. Cancer Treat Reports 1985; 64: 342-3.

2 Maiche A G, Lappalainen K, Teerenhovi L. Renal insufficiency in patients treated with high dose insufficiency in patients treated with

3 Stark A, Jackson G, Carey P, Arfeen S, Proctor S. Severe toxicity due to intermediate-dose methotrexate. Cancer Chemother Pharmacol 1989; 24: 243-5.

4 Stewart C F, Fleming R A, Germain B F, Seleznick M J Evans W E. Aspirin alters methotrexate disposition in rheumatoid arthritis patients. Arthritis Rheum 1991; 34 1514-8.

5 Müller-Suur R, Magnusson G, Bois-Svensson I, Jansson B. Estimation of technetium $99 \mathrm{~m}$ mercaptoacetyltriglycerine plasma clearance by use of one single plasma sample. Eur f Nucl Med 1991; 18: 28-31.

6 Bröchner-Mortensen J, Rödbro P. Selection of routine method for determination of glomerular filtration in adul patients. Scand f Clin Lab Invest 1976; 36: 35-43.

7 patients. Scand F Clin Lab Invest 1976; 36: 35-43. determination of glomerular filtration rate. Scand $\mathcal{f}$ Clin Lab Invest 1972; 30: 271-6.

8 Seideman P, Sollevi A, Fredholm B B. Additive renal effects of indomethacin and dipyridamole in man. Br $₹$ Clin Pharmacol 1987; 23: 323-30.

9 Bubeck J R. Technetium- ${ }^{-9} \mathrm{~m}$ labeled renal function and imaging agents: II. Clinical evaluation of ${ }^{99} \mathrm{~m}$ Tc-MAG$3\left({ }^{99} \mathrm{~m}\right.$ Tc mercaptoacetylglycylglycylglycine). Int $\mathcal{f}$ Rad Appl Instrum 1988; 15: 109-18.

10 Müller-Suur R, Müller-Suur C. Glomerular filtration and tubular secretion of MAG-3 in the rat kidney. $¥ \mathrm{Nucl} \mathrm{Med}$ 1989; 30: 1986-91.

11 Dubovski and Russel. ${ }^{99} \mathrm{~m}$ Tc-MAG-3: The multipurpose renal radio pharmaceutical. In: Freeman L M, ed. Nuclear medicine annual 1991. New York: Raven Press, 1991: medici.

12 Grigor R R, Spitz P W, Furst D E. Salicylate toxicity in elderly patients with rheumatoid arthritis. $f$ Rheumatol 1987; 14: $60-6$. 